\section{TREAT RECEDING GUMS}

With innovative in-house dental solutions developed and created based on clinical evidence, the team at CosTech Elite Dental Laboratory work hard to bring you superior products and quality solutions.

Professionals understand the damaging effects untreated gingivitis can have. As gums pull away from the teeth and form pockets that are infected, bacterial toxins and the body's enzymes fighting the infection actually start to break down the bone and connective tissue that hold teeth in place. Once the disease has been controlled, prescribing Gingiflex $^{\mathrm{TM}}$ will give your patients the confidence to smile again.

The incredible GingiFlex ${ }^{\mathrm{TM}}$ is a flexible gum façade that can be easily used by

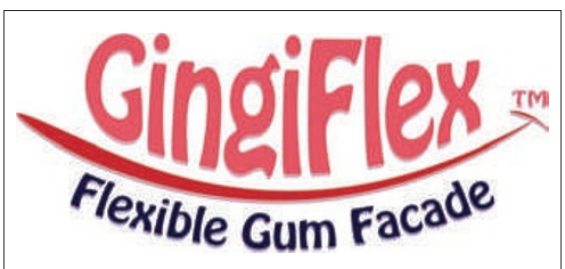

patients to treat receding gums. Gingiflex ${ }^{\mathrm{TM}}$ covers the exposed teeth and unsightly gaps and has flexible properties that allow easy placement and removal for cleaning. It is unbreakable under normal use, has a comfortable 'soft feel' and a natural colour to perfectly match the gum.

Built on innovation, dedication and communication, CosTech Elite is passionate about its work, so you can deliver outstanding results in yours.

Reader response number 57

\title{
NATURAL OCCLUSIONS WITH JUST ONE CLICK
}

Sirona Dental Systems are pleased to announce the benefits that the CEREC AC Bluecam CAD/CAM system in conjunction with the new Biogeneric software offers to the dental practice.

CEREC Biogeneric revolutionises occlusal surface design. It is the first restoration method which metrically analyses the patient's individual dentition status as the basis for computing the occlusal morphology. This patented scientific procedure is the passport to natural, made-to-measure restorations founded on precise metric principles. What is more, this method is extremely simple. With a single mouse click the user is able to create crowns, veneers, inlays and onlays, as well as anatomically sized bridges with up to four units.

CEREC significantly improves the quality of treatment for patients as well as enhancing the efficiency of the dental practices, saving time for you and your patients and drastically reducing laboratory bills.

Reader response number 58

\section{PERFECT AESTHETICS WITH DENTAL SKY}

With an impressive compressive strength of $469 \mathrm{MPa}$, Dental Sky's Itena Perfect Feel nano-hybrid composite material is fast becoming the restorative of choice.

Available in a good selection of shades, Perfect Feel is ideal for all anterior and posterior applications. It has a high filler content meaning that shrinkage and postoperative sensitivity is minimised, with a high lustre to the finished restoration. With optimised translucence, Perfect Feel's dentine and enamel opacities are combined to produce a chameleon-like one shade layering procedure with unsurpassed aesthetics.

Perfect Feel will not slump, which has proved to be particularly useful in the upper regions and not being sticky, the material will stay exactly where you place it without adhering to your instruments and pulling back from the cavity. This eliminates any voids within the material that may cause future problems.

Perfect Feel is supplied in either a syringe or compules for ease of use and is currently being promoted at extra special prices only through Dental Sky. Reader response number 59

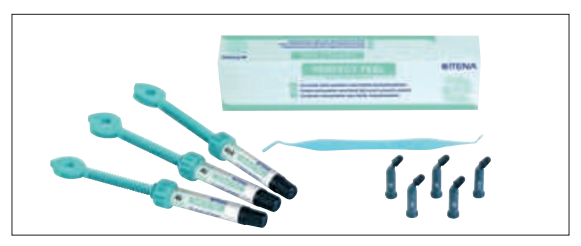

